\title{
CDC's Response to the 2014-2016 Ebola Epidemic — Guinea, Liberia, and Sierra Leone
}

\author{
Benjamin A. Dahl, $\mathrm{PhD}^{1}$ \\ Michael H. Kinzer, $\mathrm{MD}^{2}$ \\ Pratima L. Raghunathan, $\mathrm{PhD}^{3}$ \\ Athalia Christie, MIA ${ }^{3}$ \\ Kevin M. De Cock, MD ${ }^{4,5}$ \\ Frank Mahoney, $\mathrm{MD}^{1}$ \\ Sarah D. Bennett, $\mathrm{MD}^{2}$ \\ Sara Hersey, $\mathrm{MPH}^{2,6}$ \\ Oliver W. Morgan, $\mathrm{PhD}^{7}$ \\ ${ }^{1}$ Global Immunization Division, Center for Global Health, CDC \\ ${ }^{2}$ Division of Global Health Protection, Center for Global Health, CDC \\ ${ }^{3}$ Office of the Director, Center for Global Health, CDC \\ ${ }^{4}$ Division of Global HIVIAIDS and Tuberculosis, Center for Global Health, CDC \\ ${ }^{5}$ Country Director, CDC Kenya \\ ${ }^{6}$ Country Director, CDC Sierra Leone \\ ${ }^{7}$ Division of Preparedness and Emerging Infections, National Center for Emerging and Zoonotic Infectious Diseases, CDC
}

Corresponding author: Benjamin A. Dahl, Global Immunization Division, Center for Global Health, CDC. Telephone: 404-639-0972; E-mail: BDahl@cdc.gov.

\section{Summary}

CDC's response to the 2014-2016 Ebola virus disease (Ebola) epidemic in West Africa was the largest in the agency's history and occurred in a geographic area where CDC had little operational presence. Approximately 1,450 CDC responders were deployed to Guinea, Liberia, and Sierra Leone since the start of the response in July 2014 to the end of the response at the end of March 2016, including 455 persons with repeat deployments. The responses undertaken in each country shared some similarities but also required unique strategies specific to individual country needs. The size and duration of the response challenged CDC in several ways, particularly with regard to staffing. The lessons learned from this epidemic will strengthen CDC's ability to respond to future public health emergencies. These lessons include the importance of ongoing partnerships with ministries of health in resource-limited countries and regions, a cadre of trained CDC staff who are ready to be deployed, and development of ongoing working relationships with U.S. government agencies and other multilateral and nongovernment organizations that deploy for international public health emergencies. CDC's establishment of a Global Rapid Response Team in June 2015 is anticipated to meet some of these challenges.

The activities summarized in this report would not have been possible without collaboration with many U.S. and international partners (http://www.cdc.gov/vhflebolaloutbreaks/2014-west-africalpartners.html).

\section{Overview of Response}

The Ebola virus disease (Ebola) epidemic in West Africa (Figure 1) began in late 2013 in Guinea (1) and quickly spread to neighboring countries during early 2014. The epidemic is believed to have originated as an epizootic case of Ebola in Guinea (1) that led to local person-to-person spread of disease, initially in remote semirural areas of West Africa. However, with subsequent introductions of Ebola into urban areas, new cases occurred rapidly, and contacts moved across borders, facilitating uncontrolled spread.

Early international aid provided by the World Health Organization (WHO), Médecins Sans Frontières (MSF), and CDC initially appeared to help curtail the outbreak in March and April 2014. However, with movement of untracked contacts across borders facilitating uncontrolled spread, public health authorities realized in June that the outbreak was not contained. By mid-2014, the situation had evolved into an international public health crisis as the first documented multicountry Ebola epidemic. Ongoing transmission occurred in multiple districts in Guinea, Liberia, and Sierra Leone, including in these countries' densely populated urban areas (2).

Before this epidemic, CDC presence in all three countries was very limited, and most early support for the response was provided through short-term (4- to 6-week) assignments of staff from headquarters in Atlanta, Georgia, and CDC's international country offices. In response to the evolving crisis, on July 9, 2014, CDC activated its Emergency Operations Center (EOC) and committed agency support to assist the governments of Guinea, Liberia, and Sierra Leone. Deployed staff comprised epidemiologists, data managers, public health advisors, laboratory 


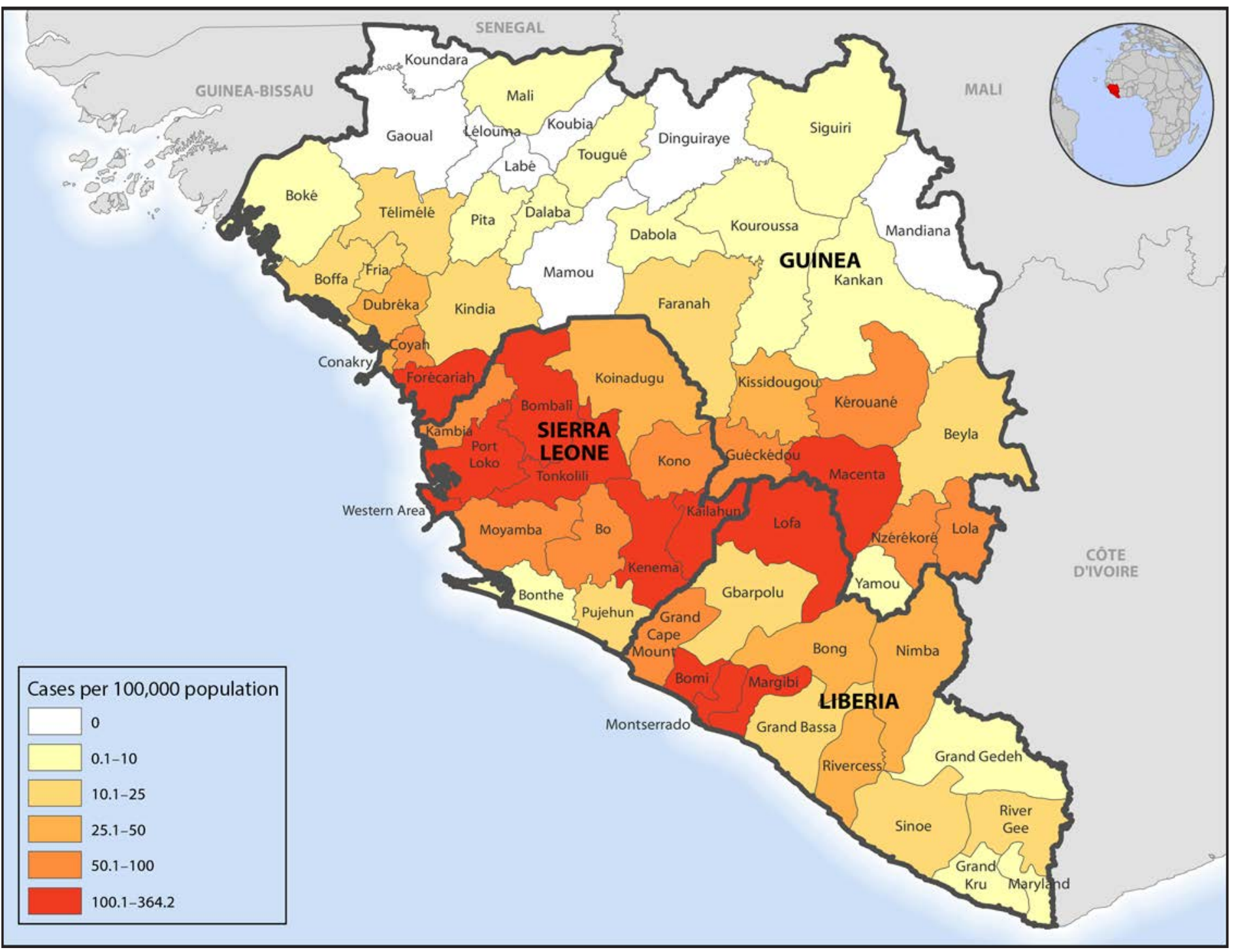

Abbreviation: Ebola $=$ Ebola virus disease.

scientists, communication experts, logistic and administrative support staff, and diverse technical support staff (3).

CDC established in-country Ebola teams in collaboration with the U.S. Agency for International Development (USAID) Disaster Assistance Response Team. This team worked with host country governments and partners as a key advisor on overall response management, including support for establishing EOCs by using an incident management system (IMS) (4). External partners working with this IMS (and with each other) included CDC, WHO, MSF, USAID, and United Nations agencies. The concept of a unified command to manage the response was new in all three of the countries most heavily affected, and the governments of these countries had no previous experience managing a complex outbreak that evolved into a humanitarian crisis. CDC teams worked within this unique and evolving structure to tailor activities to individual country needs, collaborating closely with WHO and the lead epidemiologist in the ministries of health.

CDC staff were deployed to Guinea and Liberia in March 2014 (Figure 2); in July, deployments were increased through the activation of CDC's EOC. In each country, CDC staff provided technical support and guidance to the working groups involved with epidemiology and surveillance; case investigation; laboratory capacity; safe transport of patients suspected of having Ebola, dead bodies, and laboratory specimens; infection control; community engagement; and safe burials. As the response evolved and the number of CDC staff in each country increased (Figure 2), CDC-supported 
FIGURE 2. Number of staff deployments by CDC for the Ebola epidemic, by country and month - Guinea, Liberia, and Sierra Leone, March 2014-March 2016

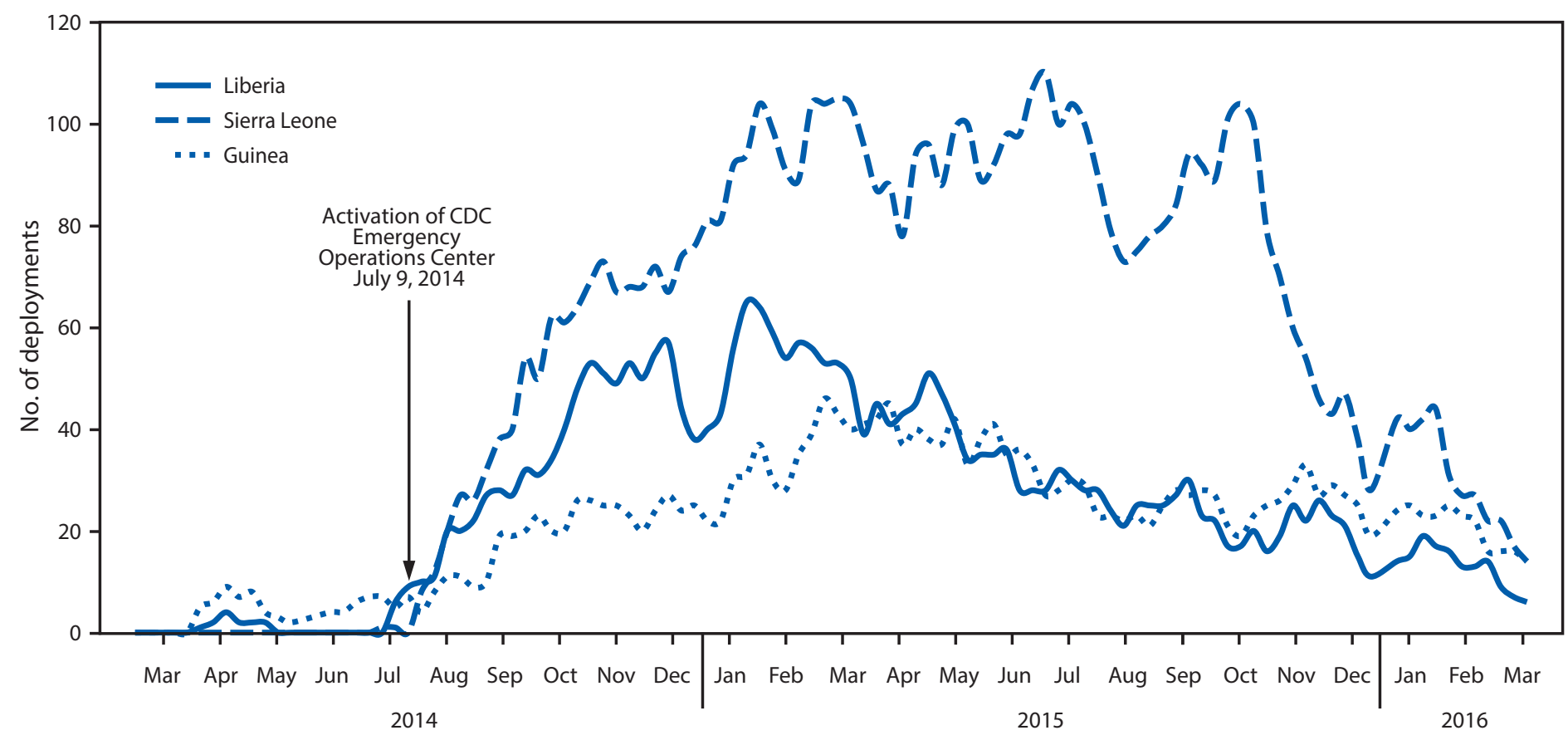

Month and year of deployment

Abbreviation: Ebola $=$ Ebola virus disease

staff (3) were deployed to outbreak areas to support ministry of health teams conducting case investigations, outbreak investigations, and various field surveys in collaboration with WHO, UNICEF, and MSF; epidemiologists were deployed through the African Union. CDC played an important role in case finding in all three countries by training staff to conduct surveillance activities and by training lead surveillance persons at the county (Liberia), district (Sierra Leone), and prefecture (Guinea) level. CDC did not send staff to provide direct patient care but did organize a training course and center for clinicians who had been deployed to work in Ebola treatment units (ETUs) in the countries affected by Ebola (5).

To maintain the large number of personnel for a long period, CDC drew on staff from its headquarters in Atlanta, Georgia, and from other CDC offices and institutes across the United States (e.g., the National Institute for Occupational Safety and Health in Cincinnati, Ohio, and the National Center for Health Statistics in Hyattsville, Maryland) and from the many CDC offices in countries around the world. In addition, CDC recruited domestic public health professionals from state health departments, fellowship programs in the United States, and other agencies within the U.S. Department of Health and Human Services. For the response in Guinea, the number of French-speaking CDC experts was augmented substantially with the deployment of colleagues from the Public
Health Agency of Canada (PHAC) and graduates of the Field Epidemiology Training Program (FETP), particularly from the Democratic Republic of the Congo. Given CDC's need to continue its ongoing work in many other areas of public health, many of the CDC experts were deployed on 4- to 6 -week rotations; 455 persons were deployed more than once.

In all three countries, the general response emphasized active surveillance, rapid case investigation, referral of patients with suspected Ebola for treatment in ETUs, contact ascertainment and follow-up, infection control, and safe burials. Although the responses in the three countries were often similar, important differences and approaches also existed in accordance with the stage of the epidemic in each country, the unique cultural influences and language barriers, and variable levels of international aid and partners available in each country.

\section{Guinea}

The Ebola epidemic is believed to have begun as a small outbreak in the Guéckédou prefecture of Guinea in late 2013, and cases spread to the capital city, Conakry, by March 2014 (2). CDC teams arrived in March to work with WHO and the Guinean government. CDC staff stayed through April, when the outbreak seemed to be waning. However, cases occurred 
again, and CDC orchestrated a more robust response to assist the Guinean government and other partners. CDC Guinea team numbers fluctuated daily and ranged from two in May 2014 to 38 in March 2015 (Figure 2). By March 31, 2016, CDC had made 568 deployments to Guinea (Table).

Several different ministries of the Guinean government managed the early response; CDC, WHO, and other partners offered primarily technical support. In September 2014, the response was reorganized into an IMS structure in which CDC and WHO provided technical assistance. The response was organized into five activities known as pillars, each of which was co-led by a Guinean national alongside an experienced partner: surveillance (WHO), care and treatment (MSF), sanitation (International Federation of Red Cross), communication (UNICEF), and research (a Congolese professor). The pillar co-leads convened technical working groups to support the needs of the response. The former head of the Epidemiology and Disease Surveillance section of Guinea's Ministry of Health and Public Hygiene led the National Ebola Coordination Cell. Although WHO was the main surveillance lead, CDC staff provided substantial technical leadership at both central and prefectural levels, focusing on support for case finding, contact tracing, case investigation, contact listing, investigation and documentation of chains of transmission, and support for improving rigor and oversight in investigating cross-prefecture and cross-border movements of contacts. Early in the epidemic, CDC staff assisted Guinean officials with exit screening at Conakry Airport; once that was effective, they shifted to monitoring terrestrial movements (especially between Forécariah prefecture and Kambia district in Sierra Leone and Boké prefecture and in Tombali region of Guinea-Bissau). CDC, challenged by a limited number of French-speaking staff in Atlanta, recruited French-speaking staff internally within the U.S. government from other CDC country offices, CDC locally employed staff, and the U.S. Department of Health and Human Services and externally through PHAC and Democratic Republic of the Congo FETP graduates and residents. The external partnerships with PHAC and Democratic Republic of the Congo FETP yielded particularly experienced and effective staff who were linguistically and culturally well adapted to the fluid field epidemiology environment.

In Guinea, as in Liberia and Sierra Leone, CDC staff did not play a direct role in Ebola treatment but did collaborate with health care workers and health care facilities on surveillance and community outreach. MSF, the French Red Cross, the African Union in collaboration with the Cuban Brigade, and Alliance for International Medical Action were the primary operators of the ETUs in Guinea. The French military also established and ran a 10-bed ETU designated for Ebola-infected care providers
TABLE. Number of confirmed (with date), probable, and suspected Ebola cases; number of deaths; and number of CDC staff deployments during the Ebola epidemic - Guinea, Liberia, and Sierra Leone, March 2014-March 20, 2016

\begin{tabular}{lrrr}
\hline Characteristic & \multicolumn{1}{c}{ Guinea } & \multicolumn{1}{c}{ Liberia } & Sierra Leone \\
\hline Date of first confirmed case & March 2014 & March 2014 & May 2014 \\
No. of confirmed, probable, & 3,811 & 10,675 & 14,124 \\
and suspected cases & & & \\
No. of deaths & 2,543 & 4,809 & 3,956 \\
No. of CDC staff & 568 & 627 & 1,100 \\
deployments & & & \\
\hline
\end{tabular}

Abbreviation: Ebola = Ebola virus disease.

(e.g., medical staff, ambulance drivers, and traditional healers) (G). The U.S. Embassy and USAID's Office of U.S. Foreign Disaster Assistance played key roles in negotiating locations and funding new ETU construction.

A marked reticence among Guinean residents to report suspected Ebola cases hampered an early effective response; when the initial outbreak seemed to be waning, cases probably were unreported $(7,8)$. Community resistance at times challenged the response and accessibility to villages. Deep-seated distrust of the government and outsiders and misconceptions in the country about the disease and the responders drove lack of reporting and, in some cases, hostility toward responders. In September 2014, villagers killed eight response workers, comprising WHO staff, doctors, and journalists (9), an event that underscored the dangerous nature of working in an atmosphere driven by fear, disbelief in the existence of the disease, and distrust of authorities. To address the reticence, several approaches were undertaken by the response IMS, including working with village elders, engaging Conakry residents who had family in the villages, deploying social anthropologists as members of investigation teams, and using security forces to maintain the peace.

In Guinea, WHO, CDC, and MSF advocated community outreach, active case finding, contact tracing, and rapid transport of patients suspected of having Ebola to ETUs rather than the widespread construction of unstaffed ETUs. This strategy markedly differed from the strategy adopted in Liberia and Sierra Leone, where construction of ETUs was a primary international focus. In Guinea, the national strategy of enhanced surveillance was anchored by the hiring of teams of recently graduated Guinean doctors who were deployed in each prefecture under the leadership of a prefectural lead. CDC and WHO deployed staff to the prefectures heavily affected by Ebola to offer technical and supervisory assistance. In the early stages, case finding was conducted through prefecture-wide door-to-door sensitization visits to raise community awareness of the urgent need to report patients suspected of having Ebola. Later, Ebola case finding in Guinea was intensified to include door-to-door monitoring in high-incidence subprefectures. 
At this stage, contacts of Ebola patients were monitored with daily temperature checks but were not physically or socially restricted from traveling to other prefectures.

The continued seeding of new chains of transmission in prefectures that had previously been free of Ebola led the Guinean National Ebola Response to adopt an approach called cerclage to contain the outbreak (10). This approach was an attempt to limit the movement of contacts of recent Ebola patients and their associated communities through social pressure and encouragement to remain within a circumscribed area (home or their village). To ensure community participation with the restrictions on movement, the national Ebola response provided some essential medical services, as well as supplemental food and hygiene materials. Village leaders were engaged and asked whether they agreed to participate in the cerclage. Prefectural Ebola response teams continued to directly observe the contacts each day during the 21-day follow-up period to rapidly isolate newly symptomatic patients. This approach was partially adapted from the Rapid Isolation and Treatment of Ebola (RITE) strategy $(11,12)$ in Liberia and the quarantine village approach from Sierra Leone.

WHO declared Guinea free of Ebola transmission on December 29, 2015, after the last Ebola patient in Guinea was discharged from an ETU on November 16, 2015. On March 17, 2016, a new case of Ebola was reported in Guinea, and related cases were subsequently identified in both Guinea and Liberia. CDC expected that sporadic cases of Ebola could occur, even after the epidemic had ended, and cases have indeed occurred in Guinea, Liberia, and Sierra Leone since the epidemic was declared over in each country.

\section{Liberia}

A team of seven CDC staff members arrived in Monrovia in mid-July 2014 after a request for assistance from Liberia's Ministry of Health and Social Welfare. Events in late July that drew the world's attention to the emergency in West Africa included travel by an infected person from Monrovia to Lagos, Nigeria, initiating a secondary outbreak there, and Ebola infection in U.S. and other expatriate health care workers and their subsequent international evacuation (13). Within weeks, considerable additional staff were deployed; by September 2014, the CDC team in Liberia comprised approximately 40 persons. Initial investigations in July 2014 focused on determining the extent and magnitude of the outbreak, including among health care workers; clarifying and strengthening data systems and reporting; coordinating enhancement of laboratory capacity; and providing overall support for the Liberian response (14-16).
In early August 2014, the gravity of the situation was recognized. The U.S. ambassador declared a disaster, the president of Liberia declared a state of emergency (14-16), and WHO called the Ebola epidemic a public health emergency of international concern (14). An important contribution by the CDC team in late July 2014 was advising the Ministry of Health and Social Welfare on establishing a focused IMS to replace the previous Liberian Ebola Task Force, a task force that was large and included high-level officials within the government $(17,18)$. After formation of the IMS, the following priorities were established: 1) early detection and isolation of persons with Ebola, 2) safe transport of patients with suspected Ebola, 3) support of infection control to prevent transmission within the health care system, and 4) safe burials. Isolation of patients with suspected Ebola was the most immediate and overriding objective. The strategy did not include treatment of patients within existing health facilities (but supported homebased care instead) and did not use involuntary quarantine for contacts of patients. Involuntary quarantine by the authorities of a particularly impoverished community in Monrovia in mid-August 2014 resulted in violence, was not supported by technical partners, and was not repeated (19).

IMS proved critical to consolidate, communicate, and ensure broad support for technical and policy interventions. However, the system remained larger than ideal. Therefore, the incident manager set up an inner core of advisors comprising representatives from WHO, CDC, and the UN Mission for Ebola Emergency Response, who conferred daily to discuss priority activities and make key decisions. The Liberian EOC organized a series of microplanning (county-level response) workshops with key county health officials and partners to assist in planning and developing response capacity.

WHO co-chaired the case management working group, and CDC played an important role in supporting the evolving case management strategy. U.S. government efforts focused on building ETUs to manage the increasing caseload of patients, although those efforts were not managed by CDC staff. Several partners contributed to the building of ETUs; however, delays in construction and mobilization of resources to staff and supply the ETUs hampered efforts. In response to the increasing number of patients suspected of having Ebola and requiring urgent management and care, CDC and others supported establishment of community care centers in areas without ETUs. The increase in available isolation beds and expanded efforts to ensure rapid and safe burials markedly reduced Ebola incidence, and by late September 2014, national bed capacity exceeded demand (20).

During late October and early November 2014, numerous outbreaks occurred in remote areas of Liberia. The need for flexible, mobile, and rapid teams that could quickly reach new hot spots, conduct assessments, and implement early control 
measures was recognized, leading to development of the RITE strategy $(11,12)$. RITE teams were deployed at the first report of new suspected outbreaks, and team members focused on village-level isolation and management of patients until safe referral to ETUs could be established. The enhanced capacity of county health teams to investigate outbreaks in remote areas provided a faster, more tailored response to the local needs.

In addition to supporting the national surveillance office, CDC deployed staff and tried to maintain a presence in all counties within Liberia that had ongoing Ebola virus transmission. Much of the work at the county level focused on developing surveillance and data management capacity of the county health team and supporting contact tracing and outbreak investigations. Effort also went into health communication (17).

By November 2014, the epidemic was characterized by continued low-level transmission in Monrovia and surrounding Montserrado County, which resulted in sporadic cases in remote, rural locations. Cases had declined substantially, enabling focus on individual transmission chains. The last known chain, in a community near Saint Paul River Bridge, was investigated and contained in early 2015 (21). Although Liberia appeared on the way to being declared Ebola-free, one case occurred unexpectedly in Monrovia in March 2015. A detailed investigation found that the patient most likely acquired Ebola through sexual intercourse with an Ebola survivor who had been ill approximately 6 months previously $(22,23)$.

Liberia was first declared free of Ebola transmission by WHO on May 9, 2015, and on two subsequent occasions (September 3, 2015, and January 14, 2016), only to have other clusters or cases subsequently detected and contained. CDC staff are now concentrating on strengthening epidemiology, laboratory capacity, infection prevention and control, and restoration of routine health services.

\section{Sierra Leone}

The first cases of Ebola in Sierra Leone were detected in May 2014. Transmission increased from the eastern Kailahun and Kenema districts early in the outbreak to eventually affect all 14 districts. CDC's first deployment to Sierra Leone occurred in July 2014 (Figure 2); 1,100 deployments supported CDC activities in the country through March 20, 2016 (Table).

CDC provided technical assistance to the government of Sierra Leone and many partners to implement outbreak management activities. To support these activities, CDC staff were embedded into the local response teams at the District Ebola Response Centres and into the national-level National Ebola Response Centre and Ministry of Health and Sanitation (MoHS).

CDC supported establishment and management of the national and district databases and provided data management and technical assistance for Ebola surveillance, case investigation, contact tracing, and other outbreak control activities. CDC staff helped with training and supportive supervision of case investigators, contact tracers, and data managers and contributed subject-matter expertise to the investigations of nosocomial Ebola outbreaks and infections among health care workers and frontline responders. The MoHS used CDC's concept of Ring Infection Prevention and Control (Ring IPC) (24), and CDC was integral to implementing the strategy; this strategy supported improved screening, isolation, referral for treatment, use of hand hygiene and personal protective equipment, waste management, and cleaning and decontamination practices for health care facilities and health care workers at highest risk for Ebola exposure and infection. CDC staff commonly coordinated Ring IPC activities in collaboration with WHO, the United Kingdom's Department for International Development, and nongovernment organizational partners. Finally, CDC staff supported rapid behavioral assessments to inform ongoing response activities and improve community engagement.

The MoHS, the International Organization for Migration, and $\mathrm{CDC}$ worked to strengthen screening at the international airport and seaports and along land borders. CDC also supported development of guidelines, training of screeners and management staff, periodic assessments with support to address gaps identified, and exercises to maintain procedures throughout the epidemic.

Unlike in Guinea and Liberia, in Sierra Leone CDC established, managed, and staffed an Ebola testing laboratory. Initially the laboratory was in Kenema district but was later relocated to Bo district, with an MSF ETU. The CDC Bo Laboratory maintained capacity to test up to a peak of 180 samples in a single day. The laboratory played a considerable role in Ebola virus diagnostic laboratory testing in Sierra Leone, processing more than one third of all specimens during the epidemic, and had tested approximately 26,000 specimens when it was closed in October 2015. In addition to diagnostic testing, the CDC Bo Laboratory also tested semen samples collected as part of the Virus Persistence Study among Ebola survivors (25). CDC supported laboratory coordination, assisted with the development of sample transport and data reporting systems, and provided support to MoHS to conduct proficiency testing of international Ebola laboratories in Sierra Leone. As of March 31, 2016, CDC continued to provide technical assistance to the government of Sierra Leone and other partners to sustain laboratory capacity for Ebola virus testing and to strengthen government of Sierra Leone laboratory systems at the Central Public Health Reference Laboratory in Freetown. 
Throughout the epidemic, CDC collaborated with MoHS and the Ebola Response Consortium, which comprised nongovernment organizations, to enhance screening, isolation, and referral capacity at non-Ebola health care facilities. Activities reached 1,188 government clinics and resulted in training of 4,264 health care workers on infection-control procedures (26) relevant to the outpatient setting, including screening, isolation and temporary management, referral for testing, hand washing, use of recommended personal protective equipment, waste management, and cleaning and decontamination. At government hospitals, CDC supported MoHS and WHO in the placement and training of IPC focal persons and committees (5). Within MoHS, CDC and WHO assisted with establishing the National IPC Unit, led by a national IPC coordinator. The National IPC Unit is responsible for expanding Ebola IPC activities to all public and private health care facilities and to include practices to reduce nosocomial transmission of pathogens other than Ebola virus.

With MoHS and other partners, CDC participated in several studies during the Ebola response, including the Sierra Leone Trial to Introduce a Vaccine against Ebola (27). In addition, with MoHS and WHO, CDC initiated the Virus Persistence Study to assess the length of Ebola virus shedding in the semen of survivors (25). A second phase of the study is enrolling survivors of both sexes to determine the persistence of Ebola virus in body fluids. A household transmission study was conducted in Freetown to better understand the dynamics of Ebola virus transmission (CDC, unpublished data, 2015). Four surveys of knowledge, attitudes, and practices were conducted with CDC support at different stages during the epidemic to improve understanding of how Sierra Leone residents perceived the Ebola epidemic and response and what activities might improve community engagement. CDC also collaborated with the National Institutes of Health to implement a randomized trial of the investigational therapeutic drug ZMapp (28).

Sierra Leone had two new cases beginning in January 2016, more than 2 months after WHO declared the end of the epidemic in Sierra Leone on November 7, 2015. Rapid and effective contact tracing, as well as implementation of control measures, quickly controlled the sporadic clusters that have occurred.

\section{Challenges and Lessons Learned}

Key challenges to the countries affected by Ebola as the epidemic accelerated included response coordination, initial clinical management and isolation of patients suspected of having Ebola, development of a reliable alert system to report suspected cases, development of a skilled workforce for field epidemiologic investigation, and the need for infrastructure to manage and isolate contacts. Early in the epidemic, all three countries found it challenging to reach a consensus among partners on specific strategies for the overall response. Other challenges included 1) developing treatment protocols and scaling up health systems' capacity to manage the growing number of patients; 2) deciding whether to use existing facilities or build new facilities for clinical care, whether to support home-based care, and the role of quarantine in managing cases and contacts; 3) developing communication strategies; 4) determining how to engage communities and enlist their support; and 5) deciding how to respond to the increasing humanitarian crisis. Another challenge included producing reliable descriptive epidemiologic data, which underscored the need for standardization of data collection and management between the three countries.

A major issue for all three countries was the extensive and substantial effect of the epidemic on basic health care services. For example, nosocomial transmission led to Ebola virus infection among staff members, routine vaccination campaigns were canceled, samples from persons suspected of having polio were unable to be transported out of the countries, and 75\% fewer caesarean sections reportedly were performed than before the Ebola epidemic $(29,30)$. As the epidemic has waned, the need to rebuild the health care sector has become apparent.

Many unique staffing challenges and solutions were encountered during this historic response, the largest in CDC's history. Approximately 1,400 CDC staff were placed in the three countries during the 21 months of the EOC activation, during July 2014-March 2016. This long-term need for international deployment of staff highlighted that CDC's traditional approach to international work (deployments of approximately 30 days) might need to be reconsidered for future responses of this magnitude and length. Positive relationships with different partners must continue to be fostered, and clear objectives for CDC roles and responsibilities for outbreak responses should be determined before the next outbreak.

The 2014-2016 Ebola epidemic in West Africa underscores the importance of ongoing partnerships with ministries of health in resource-limited countries and regions. The rapid response to the initial introduction of Ebola into Nigeria, where CDC had an established presence (3), contrasts considerably with that of the early CDC response in Guinea, Liberia, and Sierra Leone. Issues to consider while attempting to enhance CDC's capacity in overseas public health emergency responses of this magnitude include providing effective, internationally focused emergency response training; maintaining a cadre of culturally and linguistically fluent, highly experienced staff who are ready to be deployed to other countries; and developing ongoing working relationships with U.S. government agencies and other multilateral and nongovernment organizations that 
deploy during international public health emergencies. CDC's establishment in June 2015 of the Global Rapid Response Team, which includes staff members who are on call and ready to deploy at any given time to Africa, the Middle East, and Asia, is anticipated to meet many of these challenges.

\section{Conclusion}

The response to the Ebola epidemic in Guinea, Liberia, and Sierra Leone varied by country and involved many international partners working with government ministries. However, across the region, CDC staff were primarily engaged in offering subject-matter expertise on the core principles for control, including ensuring and enhancing surveillance efforts across the region, and ensuring prompt, efficient, and complete contact tracing practices. In addition, CDC provided technical support in other areas, offering guidance, training, and support for infection-control and health communication. Although the response varied among countries and changed as the epidemic shifted, a common goal, to reach zero new Ebola cases, drove the response within each country and among all partners, as did the belief that such a goal was attainable.

A CDC operational presence earlier in the epidemic might have led to a more effective response. Therefore, CDC has established country offices in Guinea, Liberia, and Sierra Leone to help the ministries of health better prepare for future disease outbreaks. These new in-country offices will focus on building surveillance capacity by strengthening the public health infrastructure, expanding the workforce, improving laboratories, and continuing to develop emergency response capability.

\section{References}

1. Baize S, Pannetier D, Oestereich L, et al. Emergence of Zaire Ebola virus disease in Guinea. N Engl J Med 2014;371:1418-25. http://dx.doi. org/10.1056/NEJMoa1404505

2. Dixon MG, Schafer IJ; CDC. Ebola viral disease outbreak-West Africa, 2014. MMWR Morb Mortal Wkly Rep 2014;63:548-51.

3. Frieden TR, Damon IK. Ebola in West Africa-CDC's role in epidemic detection, control, and prevention. Emerg Infect Dis 2015;21:1897-905. http://dx.doi.org/10.3201/eid2111.150949

4. Brooks JC, Pinto M, Gill A, et al. Incident management systems and building emergency management capacity during the 2014-2016 Ebola epidemic-Liberia, Sierra Leone, and Guinea. In: CDC response to the 2014-2016 Ebola epidemic-West Africa and United States. MMWR Suppl 2016;65(No. Suppl 3).

5. Hageman JC, Hazim C, Wilson K, et al. Infection prevention and control for Ebola in health care settings-West Africa and United States. In: CDC response to the 2014-2016 Ebola epidemic-West Africa and United States. MMWR Suppl 2016;65(No. Suppl 3).

6. Janvier F, Foissaud V, Delaune D, et al. Deployment of the French military field laboratory dedicated to Ebola virus infected patients in Guinea, January-July 2015. J Infect Dis 2016;213:1208-9. http://dx.doi. org/10.1093/infdis/jiv554
7. Dixon MG, Taylor MM, Dee J, et al. Contact tracing activities during the Ebola virus disease epidemic in Kindia and Faranah, Guinea, 2014. Emerg Infect Dis 2015;21:2022-8. http://dx.doi.org/10.3201//eid2111.150684

8. Victory KR, Coronado F, Ifono SO, Soropogui T, Dahl BA. Ebola transmission linked to a single traditional funeral ceremonyKissidougou, Guinea, December 2014-January 2015. MMWR Morb Mortal Wkly Rep 2015;64:386-8.

9. Dixon R. Eight reported dead in attack on Ebola workers in Guinea. Los Angeles Times. September 18, 2014. http://www.latimes.com/world/ africa/la-fg-attack-ebola-guinea-outreach-20140918-story.html

10. Hersey S, Martel LD, Jambai A, et al. Ebola virus disease-Sierra Leone and Guinea, August 2015. MMWR Morb Mortal Wkly Rep 2015;64:981-4. http://dx.doi.org/10.15585/mmwr.mm6435a6

11. Kateh F, Nagbe T, Kieta A, et al. Rapid response to Ebola outbreaks in remote areas-Liberia, July-November 2014. MMWR Morb Mortal Wkly Rep 2015;64:188-92.

12. Lindblade KA, Kateh F, Nagbe TK, et al. Decreased Ebola transmission after rapid response to outbreaks in remote areas, Liberia, 2014. Emerg Infect Dis 2015;21:1800-7. http://dx.doi.org/10.3201/eid2110.150912

13. Forrester JD, Hunter JC, Pillai SK, et al. Cluster of Ebola cases among Liberian and U.S. health care workers in an Ebola treatment unit and adjacent hospital-Liberia, 2014. MMWR Morb Mortal Wkly Rep 2014;63:925-9.

14. Arwady MA, Bawo L, Hunter JC, et al. Evolution of Ebola virus disease from exotic infection to global health priority, Liberia, mid-2014. Emerg Infect Dis 2015;21:578-84. http://dx.doi.org/10.3201/eid2104.141940

15. Forrester JD, Pillai SK, Beer KD, et al. Assessment of Ebola virus disease, health care infrastructure, and preparedness - four counties, Southeastern Liberia, August 2014. MMWR Morb Mortal Wkly Rep 2014;63:891-3.

16. Matanock A, Arwady MA, Ayscue P, et al. Ebola virus disease cases among health care workers not working in Ebola treatment unitsLiberia, June-August, 2014. MMWR Morb Mortal Wkly Rep 2014;63:1077-81.

17. Nyenswah TG, Kateh F, Bawo L, et al. Ebola and its control in Liberia, 2014-2015. Emerg Infect Dis 2016;22:169-77. http://dx.doi. org/10.3201/eid2202.151456

18. Pillai SK, Nyenswah T, Rouse E, et al. Developing an incident management system to support Ebola response-Liberia, July-August 2014. MMWR Morb Mortal Wkly Rep 2014;63:930-3.

19. Onishi N. Clashes erupt as Liberia sets an Ebola quarantine. New York Times. August 20, 2014. http://www.nytimes.com/2014/08/21/world/ africa/ebola-outbreak-liberia-quarantine.html

20. Nyenswah T, Fahnbulleh M, Massaquoi M, et al. Ebola epidemicLiberia, March-October 2014. MMWR Morb Mortal Wkly Rep 2014;63:1082-6.

21. Nyenswah T, Fallah M, Sieh S, et al. Controlling the last known cluster of Ebola virus disease-Liberia, January-February 2015. MMWR Morb Mortal Wkly Rep 2015;64:500-4. Erratum in: MMWR Morb Mortal Wkly Rep 2015;64:806; MMWR Morb Mortal Wkly Rep 2015;64:1180.

22. Christie A, Davies-Wayne GJ, Cordier-Lasalle T, et al. Possible sexual transmission of Ebola virus-Liberia 2015. MMWR Morb Mortal Wkly Rep 2015;64:479-81. Erratum in: MMWR Morb Mortal Wkly Rep 2015;64:1180.

23. Mate SE, Kugelman JR, Nyenswah TG, et al. Molecular evidence of sexual transmission of Ebola virus. N Engl J Med 2015;373:2448-54. http://dx.doi.org/10.1056/NEJMoa1509773

24. Nyenswah T, Massaquoi M, Gbanya MZ, et al. Initiation of a ring approach to infection prevention and control at non-Ebola health care facilities_Liberia, January-February 2015. MMWR Morb Mortal Wkly Rep 2015;64:505-8.

25. Deen GF, Knust B, Broutet N, et al. Ebola RNA persistence in semen of Ebola virus disease survivors-preliminary report. N Engl J Med 2015. http://dx.doi.org/10.1056/NEJMoa1511410 
26. Levy B, Rao CY, Miller L, et al. Ebola infection control in Sierra Leonean health clinics: a large cross-agency cooperative project. Am J Infect Control 2015;43:752-5. http://dx.doi.org/10.1016/j.ajic.2015.03.011

27. Widdowson MA, Schrag SJ, Carter RJ, et al. Implementing an Ebola vaccine study — Sierra Leone. In: CDC response to the 2014-2016 Ebola epidemicWest Africa and United States. MMWR Suppl 2016;65(No. Suppl 3).

28. National Institutes of Health. Putative investigational therapeutics in the treatment of patients with known Ebola infection. Washington, DC: National Institutes of Health; 2015. https:/clinicaltrials.gov/ct2/show/ NCT02363322?term=zmapp\&rank=1
29. Elston JWT, Moosa AJ, Moses F, et al. Impact of the Ebola outbreak on health systems and population health in Sierra Leone. J Public Health (Oxf) 2015;fdv158. http://dx.doi.org/10.1093/pubmed/fdv158

30. Lori JR, Rominski SD, Perosky JE, et al. A case series study on the effect of Ebola on facility-based deliveries in rural Liberia. BMC Pregnancy Childbirth 2015;15:254. http://dx.doi.org/10.1186/s12884-015-0694-x 